Regards sur l'économie allemande

Bulletin économique du CIRAC

$118-119 \mid 2015$

Varia

\title{
Radio analogique : fin des ondes moyennes le 31-12
}

\section{Isabelle Bourgeois}

\section{OpenEdition}

Journals

Édition électronique

URL : http://journals.openedition.org/rea/4901

DOI : 10.4000/rea.4901

ISSN : 1965-0787

\section{Éditeur}

CIRAC

\section{Édition imprimée}

Date de publication : 31 décembre 2015

Pagination : $39-40$

ISSN : 1156-8992

\section{Référence électronique}

Isabelle Bourgeois, «Radio analogique : fin des ondes moyennes le 31-12 », Regards sur l'économie allemande [En ligne], 118-119 | décembre 2015, mis en ligne le 31 décembre 2017, consulté le 15 septembre 2020. URL : http://journals.openedition.org/rea/4901

Ce document a été généré automatiquement le 15 septembre 2020.

(c) CIRAC 


\title{
Radio analogique : fin des ondes moyennes le $31-12$
}

\author{
Isabelle Bourgeois
}

Dans la nuit du 31 décembre 2015, la radio Deutschlandfunk (Cologne) cessera d'émettre en ondes moyennes. Elle est la dernière de toutes les radios publiques allemandes à abandonner la bande de fréquences 531 à $1611 \mathrm{kHz}$ en usage depuis la naissance du média radio dans les années 1920. Elle s'était en effet vu accorder un sursis lié notamment à son statut particulier. Avant l'Unité allemande, sa mission était de desservir " l'Allemagne et l'Europe », c'est-à-dire d'informer les Allemands de la RDA et les pays du bloc soviétique sur l'actualité du monde occidental comme sur celle de leurs pays; or à l'ère du tout terrestre analogique, seules les ondes moyennes (connues aussi sous le nom de "petites ondes » en France) permettaient de couvrir ces moyennes distances. Après l'Unité, Deutschlandradio avait été, non sans mal d'ailleurs (voir REA 98-99/2010), transformée en la seule radio nationale existant en Allemagne. En tant que telle, elle avait également pour spécificité de diffuser par exemple l'intégralité des débats du Bundestag. L'autre raison de ce sursis réside dans son rôle de pionnier dans le développement du nouveau standard de radio numérique : $\mathrm{DAB}+$.

Aujourd'hui donc, l'Allemagne rompt avec une technologie vieille de 95 ans qui a profondément marqué de son empreinte l'histoire de la radio comme celle de la RFA. Car à l'issue de la guerre, l'Allemagne de l'Ouest s'était vu retirer lors de la Conférence européenne de Copenhague en 1948 toutes ses fréquences en ondes longues (bande 153 à $279 \mathrm{kHz}$; quelques années plus tard, la RDA s'en verra à nouveau attribuer une). Il ne restait dont plus que les ondes moyennes pour diffuser les programmes. Très vite, la radio devint inaudible (friture, fading...), ces ondes étant peu adaptées aux courtes distances, et le premier émetteur en bande FM ( 87,5 à $108 \mathrm{MHz})$ fut mis en service en février 1949. Rapidement, c'est ainsi la modulation de fréquence (FM) qui s'imposa, d'autant plus que sa faible portée s'accommodait bien avec un paysage audiovisuel très segmenté géographiquement et au plan de la réglementation (chaque Land est seul souverain sur son territoire en matière d'audiovisuel). Voilà les raisons techniques (et constitutionnelles à la fois) pour lesquelles l'Allemagne ne pouvait imaginer, avant la 
réunification, de se doter un jour d'une radio «nationale ». Dans le cadre de la fusion avec la radio nationale de l'ex-RDA et la radio américaine RIAS après l'Unité, Deutschlandfunk, qui est l'une des deux antennes qui en sont issues (l'autre est Deutschlandradio Kultur) s'était aussi vu attribuer les deux émetteurs ondes longues de la RDA.

3 Aujourd'hui donc, la modulation d'amplitude ( $\mathrm{GO}$ et $\mathrm{PO}$ ) cède le pas au numérique, la diffusion en ondes longues ayant cessé elle aussi. Reste la question de la modulation de fréquence; elle est condamnée à moyen terme. La radio sera bientôt diffusée exclusivement en DAB+ terrestre, via Internet, ou par satellite (DVB-S). En avril 2015, le ministère fédéral des Transports et des Infrastructures numériques (BMVI) a annoncé la création d'un "Board Radio numérique " (Digitalradio-Board) rassemblant tous les acteurs concernés, y compris l'industrie automobile, et chargé de définir une feuille de route pour le basculement définitif au numérique. C'est là un des chantiers de mise en œuvre de la stratégie numérique du Traité de coalition.

INDEX

Mots-clés : radio 